\title{
A Questionnaire Survey in Ehime Prefecture, Japan Revealed the Residents' Preferences for Community Medicine and Medical Education
}

Toshiaki Takahashi ${ }^{1^{*}}$, Onishi Sachiko ${ }^{1}$, Kiyonori Takada ${ }^{1}$ and Naoto Kobayashi ${ }^{2}$

${ }^{1}$ Ehime University Hospital, Community Medical Support Center Shitsukawa, Toon, Ehime, Japan ${ }^{2}$ Ehime University School of Medicine, Medical Education Center Shitsukawa, Toon, Ehime, Japan

*Corresponding author: Takahashi T, Ehime University Hospital, Community Medical Support Center, Shitsukawa, Toon, Ehime, Japan 791-0295, Tel: 089-960-5990; Fax: 089-960-5759; E-mail: takahast@m.ehime-u.ac.jp

Rec date: March 17, 2016; Acc date: April 12, 2016; Pub date: April 18, 2016

Copyright: (C) 2016 Takahashi T, et al. This is an open-access article distributed under the terms of the Creative Commons Attribution License, which permits unrestricted use, distribution, and reproduction in any medium, provided the original author and source are credited.

\begin{abstract}
Background: The lack of physicians in any given community results in very serious and ongoing deficiencies in medical service, and is a matter of considerable urgency for certain communities in Japan.

Methods: We surveyed 2812 people by questionnaire regarding community medicine in Ehime Prefecture, Japan.

Results and Conclusion: Those surveyed reported inadequate numbers of physicians in the areas of gynecology, pediatrics, internal medicine, neurosurgery, and other medical specialties. Regarding a question about the desired characteristics of a community physician, more than $50 \%$ of respondents indicated a desire for a physician who treats patients gently and kindly, can provide total care, and has extensive medical knowledge, while $15 \%$ expressed a preference for a physician with strong training in a particular field of medicine. In order to attract young physicians to the community, the majority of respondents were in favor of establishing a community hospital system that would accept those with excellent postgraduate medical training. Based on these results, it is possible to improve the medical education curriculum and to make an adequate regional policy to attract young physicians to community hospitals.
\end{abstract}

Keywords: Community medicine; Questionnaire; Medical student; Lack of physicians

\section{Introduction}

In many communities, especially those with smaller populations, the insufficient number of physicians has become a significant problem. It is very difficult to maintain the function of medical facilities such as proper primary care and emergency first aid in the rural area. Then, the progressive breakdown of community medicine systems has occurred, jeopardize residents' safety and security, and potentially lead to community collapse.

Based on the national census, Ehime Prefecture had a population of $1,431,493$ as of October 1,2010 , making it the $26^{\text {th }}$ largest prefecture in Japan. Its proportion of residents aged 65 years and older was $26.6 \%$, the $10^{\text {th }}$ highest rate in Japan and above the country's average (23\%). The number of physicians per 100,000 residents was 244.7 for Ehime Prefecture as a whole, which was slightly larger than the national average $(230.4$ per 100,000$)$. The majority of physicians worked in Matsuyama City (308.5), the capital of Ehime prefecture, while the values in the prefecture's other cities and towns were all below the national average [1].

In Ehime Prefecture, especially in mountainous and island areas, there has been significant population decline. In addition, the fact that residents are aging has contributed to the decline of local communities. Furthermore, there are many medically underserved areas and thus the enhancement of community medicine is an urgent issue. The appropriate distribution of a limited number of physicians has become an important issue not only for rural regions with population declines but also for Japan as a whole $[2,3,4]$. This supply-side decision-making often takes precedence over the demand-side realities, for instance community residents' desires for safe and adequate medical care. Previous studies have only conducted questionnaire surveys among community residents at the city or town level [5].

Ikai reported questionnaire survey regarding the concern and interest of community medicine, and eagerness of citizen's movement for improvement of community medicine in 990 peoples of Takahama rural town (population of 11,500), Japan [5]. However, we could not identify any studies performed at the prefecture level (in prefectures with a population of one million or more)

The goal of the present study was to assess the current lack of physicians in each region of Ehime Prefecture by administering a questionnaire survey about community medicine to all residents of the prefecture. The number of respondents from each region was determined by multiplying each community's population by a certain percentage.

We hope our findings will contribute to a more efficient distribution of physicians following discussion among administrating agencies, major hospitals, and community universities, as well as the medical associations of the prefecture, counties, and cities. We also solicited community residents' opinions about their expectations regarding the medical students who would be the future providers of their medical care, and about measures to attract young physicians to their communities to promote the development and reconstruction of community medicine. 
Citation: Toshiaki Takahashi, Onishi Sachiko, Kiyonori Takada, Naoto Kobayashi (2016) A Questionnaire Survey in Ehime Prefecture, Japan Revealed the Residents' Preferences for Community Medicine and Medical Education. Gen Med (Los Angeles) 4: 232. doi: $10.4172 / 2327-5146.1000232$

Page 2 of 8

\section{Materials and Methods}

We conducted an anonymous questionnaire survey of 3371 residents from all areas in Ehime Prefecture regarding their attitudes towards their community medical care and physicians. The number of subjects in each region was determined based on the region's population (a total of 20 cities and towns): 1034 people $(0.2 \%$ of all residents) for Matsuyama City (which has a total of 516,803 residents as of July 1st, 2012), and 2697 people $(0.3 \%$ of the overall number of residents) for cities other than Matsuyama City (which have a total of 899,283 residents as of July 1st, 2012). The numbers of questionnaires sent to each region were: Ainan Town, 70; Ikata Town, 31; Imabari City, 491; Iyo City, 113; Kamijima Town, 22; Kihoku Town, 34; Kumakogen Town, 28; Masaki Town, 90; Matsuno Town, 13; Matsuyama City, 1034; Niihama City, 362; Ohzu City, 138; Saijo City, 334; Seiyo City, 123; Shikokuchuo City, 267; Tobe Town, 65; Toon City, 105; Uchiko Town, 53; Uwajima City, 246; Yawatahama City, 112 (total $3,731)$, listed in alphabetical order within the prefecture.

A lower percentage of subjects were enrolled from Matsuyama City than other locations because, as it has been reported, urban areas have relatively more physicians and more adequate medical care than rural areas [1]. In early September 2012, we sent the above-mentioned numbers of questionnaires to the Division of Health and Medical Care of each city and town, and asked them to distribute and recover the sheets during relevant occasions such as events they hosted in their regions so that the participants could voluntarily respond to the questionnaires. They were also asked to send the collected questionnaires to the Community Medicine Support Center at Ehime University Hospital using collect on delivery parcels by the beginning of November 2012.

The survey items included in the questionnaire were as follows:

(1) Name of the city or town where the respondent lives (multiple choice)

(2) Age group (10-year divisions)

(3) Sex

(4) The medical facility that the respondent visits most frequently and the ones that they visit occasionally (multiple answers allowed)

(5) Methods of transportation used to travel to the most frequently visited medical facility (multiple choices)

(6) Amount of time required for each method of travel listed in item (5) (multiple choice)

(7) Factors important to the respondent in determining whether or not to visit the emergency room of a general hospital (multiple answers permitted, including "Other," which allowed for free response)

(8) Fields in which the respondent perceived a particular lack of physicians (up to three multiple-choice answers, including "Other," which allowed for free response)

(9) If the respondent answered "internal medicine" for question (8), the medical specialties in which they perceived a particular lack of physicians (up to three multiple-choice answers, including "Other," which allowed for free response)

(10) If the respondent answered "surgery" in question (8), the surgical specialties in which they perceived a particular lack of surgeons (up to three multiple-choice answers, including "Other," which allowed for free response)
(11) Expectations regarding the medical students who constitute the future of community medicine (up to three multiple-choice answers, including "Other," which allowed for free response) (i) Doctors who are familiar with state of the art medical technologies (ii) Doctors who can provide general care based on broad knowledge (iii) Doctors with strong training in a particular field of medicine (iv) Doctors who are rooted in the community (v) Doctors who are empathetic with patients (vi) Doctors who have excellent medical technique (e.g. surgical technique)

(12) Measures to be taken to attract young physicians to the respondent's community (any number of multiple-choice answers, including "Other," which allowed for free response) (i) Inviting medical students to local festivals or events (ii) Launching the city or town's own scholarship fund to attract students to the community (iii) Encouraging local high school students to go to the local university's school of medicine (iv) Increasing the salary of young physicians working at local hospitals (v) Establishing hospital systems that accept trainees

(The answer choices for questions (8), (9), and (10) were based on the classification of specializations provided by the Japan Medical Association)

This study was conducted under the Ehime Prefecture's Project on Doctor Training and Career Support 2012, and approved by the Community Medicine Promotion Committee of Ehime University Hospital. Informed consent to participate in the study was obtained from participants. The study was approved by the Ethics Committee of Ehime University Graduate School of Medicine and conducted in accordance with the Helsinki declaration.

\section{Statistical analysis}

The relationship between questions (8), (11), (12) and sex difference was statistically analyzed with a chi-square test using the SPSS software package (Tokyo, Japan). Statistical significance was found to be less than 0.05 .

\section{Results}

The total number of collected questionnaires was 2841, with a recovery rate of $76.1 \%$. There were three invalid responses and four responses that did not include the city/town name. The number of valid responses was 2812 , with a valid recovery rate (valid percentage of the total questionnaires sent to each community) of $76.0 \%$.

(1) The numbers of valid responses were as follows: Ainan Town, 68 (valid recovery rate of $97.1 \%)$; Ikata Town, 31 (100\%); Imabari City, 340 (69.2\%); Iyo City, 152 (134.5\%); Kamijima Town, 22 (100\%); Kihoku Town, 31 (91.2\%); Kumakogen Town, 25 (89.3\%); Masaki Town, 71 (78.9\%); Matsuno Town, 14 (107.7\%); Matsuyama City, 252 (24.4\%); Niihama City, 274 (75.7\%); Ohzu City, 131 (94.9\%); Saijo City, 385 (115.3\%); Seiyo City, 126 (102.4\%); Shikokuchuo City, 341 (127.7\%); Tobe Town, 45 (69.2\%); Toon City, 90 (85.7\%); Uchiko Town, 54 (101.9\%); Uwajima City, 241 (98.0\%); and Yawatahama City, 118 (105.4\%). We recovered 2560 surveys of 2697 surveys sent to locations other than Matsuyama City, and the proportion of valid respondents was $94.9 \%$.

(2) Regarding the age groups represented (10-year divisions), the largest number of respondents were in their $60 \mathrm{~s}$, followed by $50 \mathrm{~s}, 70 \mathrm{~s}$, and 30s (Figure 1). 
Citation: Toshiaki Takahashi, Onishi Sachiko, Kiyonori Takada, Naoto Kobayashi (2016) A Questionnaire Survey in Ehime Prefecture, Japan Revealed the Residents' Preferences for Community Medicine and Medical Education. Gen Med (Los Angeles) 4: 232. doi: $10.4172 / 2327-5146.1000232$

Page 3 of 8

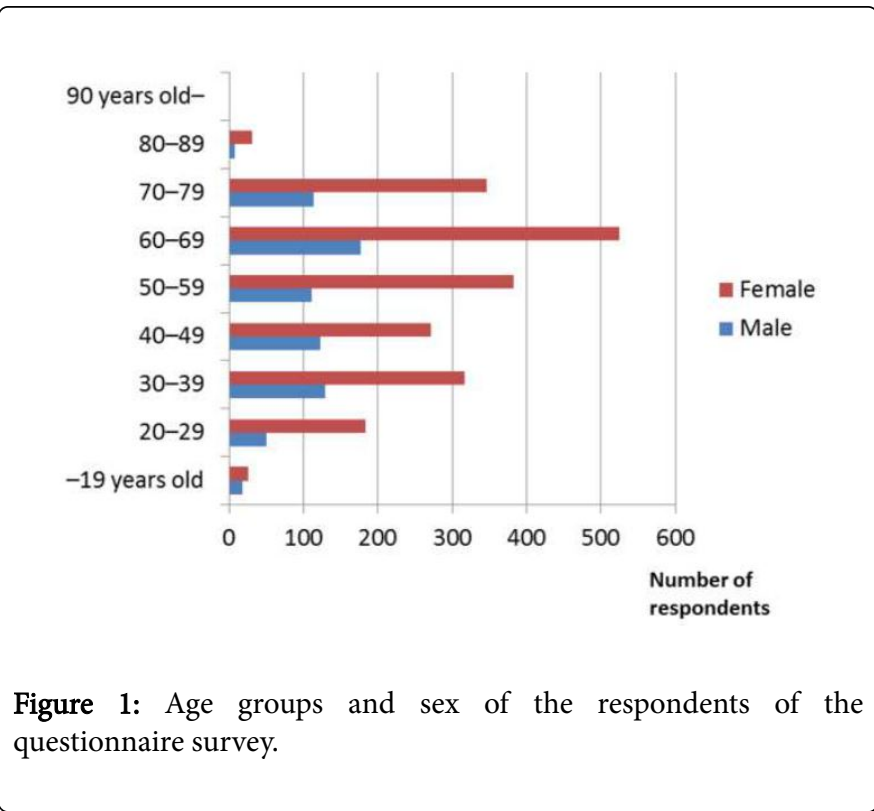

(3) Regarding the gender of respondents, more females than males responded in all age groups. The overall proportion of females in all age groups was $73.5 \%$ (Figure 1 ).

(4) The type of medical facility that respondents visited most frequently was the general hospital (total 1831; visited most frequently, 1391; visited occasionally, 440) followed by independent hospitals including private clinics (total 1494; visited most frequently, 1211; visited occasionally, 283), university hospitals (total 104; visited most frequently, 36; visited occasionally, 68), and others (total 16; multiple answers allowed).

(5) The most common method of transportation was private car (2199, $74.6 \%$ of all respondents), followed by bicycle (297, 10.0\%), motorcycle $(149,5.1 \%)$, walking $(147,5.0 \%)$, public bus $(71,2.4 \%)$, train $(56,1.9 \%)$, and taxi (30, 1.0\%) (Figure 2).

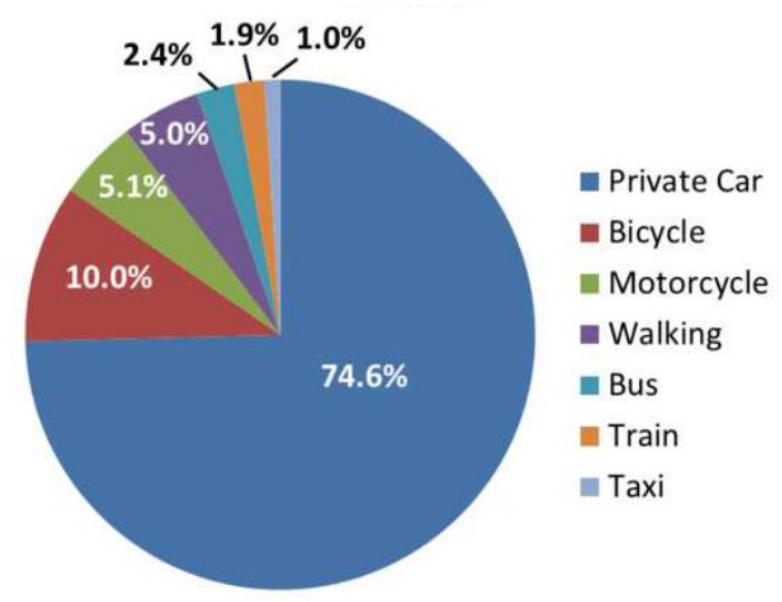

Figure 2: Methods of transportation usually used by respondents to go to the medical institutes they visited most frequently.
(6) The amount of time required for the transportation was most frequently less than 15 minutes (1579, 58.2\%), followed by $15-30$ minutes (856, 31.5\%), 30 minutes- 1 hour (211, 7.8\%), 1-2 hours (58, $2.1 \%)$, and 2 hours $(11,0.4 \%)$. These results indicate that respondents' travel times to their medical facilities were relatively short, as $90 \%$ required just 30 minutes or less (Figure 3 ).

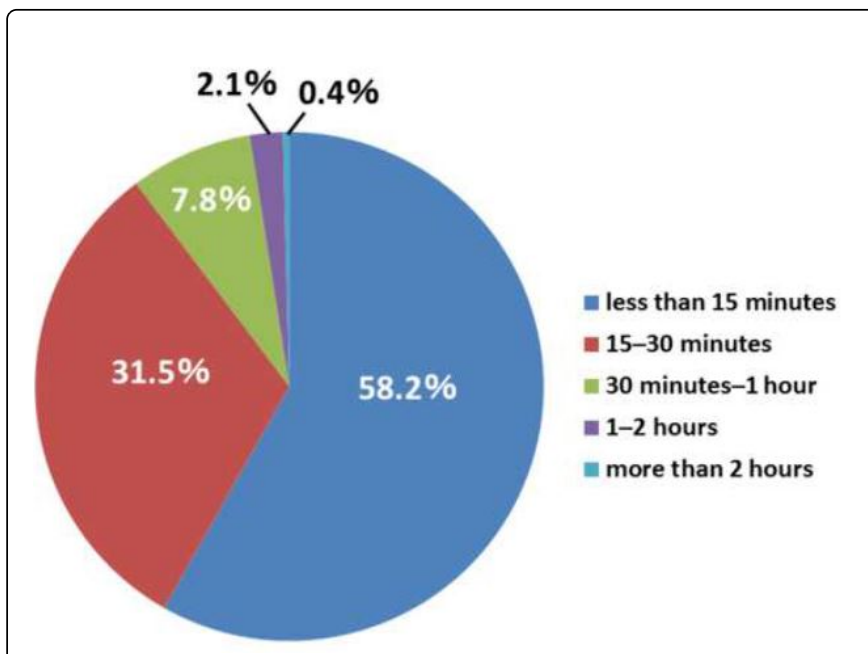

Figure 3: Amount of time required for travel to the medical institutes respondents visited most frequently.

(7) The most common factor that caused respondents to hesitate to visit the emergency room of a general hospital was "avoiding the emergency room and visiting the hospital during business hours the next day" (2089, 46.1\%), followed by "avoiding ambulance use whenever possible" (1477, 32.6\%), and "avoiding the emergency room and seeing a doctor who is on-duty during the holiday" (959, 21.2\%).

(8) Respondents perceived the most significant lack of physicians to be in the field of gynecology $(922,32.8 \%)$, followed by pediatrics $(608$, $21.6 \%)$, internal medicine $(469,16.7 \%)$, neurosurgery $(409,14.5 \%)$, emergency medicine $(329,11.7 \%)$, dermatology $(289,10.3 \%)$, surgery (265, 9.4\%), psychiatry (241, 8.6\%), ophthalmology (233, 8.3\%), orthopedics $(219,7.8 \%)$, otorhinolaryngology $(221,7.9 \%)$, oral and maxillofacial surgery $(125,4.4 \%)$, urinology (114, 4.1\%), anesthesiology $(113,4.0 \%)$, rehabilitation $(104,3.7 \%)$, plastic and reconstructive surgery $(101,3.6 \%)$, and radiology $(38,1.4 \%)$ (Table1). More women than men perceived a lack of physicians in the departments of dermatology, ophthalmology, otorhinolaryngology, and, oral and maxillofacial surgery. More men than women perceived a lack of physicians in the departments of surgery (Table 1).

\begin{tabular}{|l|l|l|l|l|}
\hline & $\begin{array}{l}\text { Total } \\
\mathbf{( 2 8 1 2 )}\end{array}$ & $\begin{array}{l}\text { Male } \\
\mathbf{( 7 3 1 )}\end{array}$ & $\begin{array}{l}\text { Female } \\
\mathbf{( 2 0 8 1 )}\end{array}$ & P value \\
\hline Gynecology & $\begin{array}{l}922 \\
(32.8 \%)\end{array}$ & $\begin{array}{l}222 \\
(30.4 \%)\end{array}$ & $\begin{array}{l}700 \\
(33.6 \%)\end{array}$ & 0.223 \\
\hline Pediatrics & $\begin{array}{l}608 \\
(21.6 \%)\end{array}$ & $\begin{array}{l}166 \\
(22.7 \%)\end{array}$ & $\begin{array}{l}442 \\
(21.2 \%)\end{array}$ & 0.407 \\
\hline Internal medicine & $\begin{array}{l}469 \\
(16.7 \%)\end{array}$ & $\begin{array}{l}135 \\
(18.5 \%)\end{array}$ & $\begin{array}{l}334 \\
(16.0 \%)\end{array}$ & 0.153 \\
\hline Neurosurgery & $\begin{array}{l}409 \\
(14.5 \%)\end{array}$ & $\begin{array}{l}107 \\
(14.6 \%)\end{array}$ & $\begin{array}{l}302 \\
(14.5 \%)\end{array}$ & 0.934 \\
\hline
\end{tabular}


Citation: Toshiaki Takahashi, Onishi Sachiko, Kiyonori Takada, Naoto Kobayashi (2016) A Questionnaire Survey in Ehime Prefecture, Japan Revealed the Residents' Preferences for Community Medicine and Medical Education. Gen Med (Los Angeles) 4: 232. doi: $10.4172 / 2327-5146.1000232$

Page 4 of 8

\begin{tabular}{|c|c|c|c|c|}
\hline Emergency medicine & $\begin{array}{l}329 \\
(11.7 \%)\end{array}$ & $\begin{array}{l}84 \\
(11.5 \%)\end{array}$ & $\begin{array}{l}245 \\
(11.8 \%)\end{array}$ & 0.838 \\
\hline Dermatology & $\begin{array}{l}289 \\
(10.3 \%)\end{array}$ & $\begin{array}{l}52 \\
(7.1 \%)\end{array}$ & $\begin{array}{l}237 \\
(11.4 \%)\end{array}$ & 0.001 \\
\hline Surgery & $\begin{array}{l}265 \\
(9.4 \%)\end{array}$ & $\begin{array}{l}84 \\
(11.5 \%)\end{array}$ & $\begin{array}{l}181 \\
(8.7 \%)\end{array}$ & 0.026 \\
\hline Psychiatry & $\begin{array}{l}241 \\
(8.6 \%)\end{array}$ & $\begin{array}{l}73 \\
(10.0 \%)\end{array}$ & $\begin{array}{l}168 \\
(8.1 \%)\end{array}$ & 0.112 \\
\hline Ophthalmology & $\begin{array}{l}233 \\
(8.3 \%)\end{array}$ & $\begin{array}{l}41 \\
(5.6 \%)\end{array}$ & $\begin{array}{l}192 \\
(9.2 \%)\end{array}$ & 0.002 \\
\hline Orthopedics & $\begin{array}{l}219 \\
(7.8 \%)\end{array}$ & $\begin{array}{l}51 \\
(7.0 \%)\end{array}$ & $\begin{array}{l}168 \\
(8.1 \%)\end{array}$ & 0.341 \\
\hline Otorhinolaryngology & $\begin{array}{l}221 \\
(7.9 \%)\end{array}$ & $\begin{array}{l}43 \\
(5.9 \%)\end{array}$ & $\begin{array}{l}178 \\
(8.6 \%)\end{array}$ & 0.021 \\
\hline $\begin{array}{l}\text { Oral and maxillofacial } \\
\text { surgery }\end{array}$ & $\begin{array}{l}125 \\
(4.4 \%)\end{array}$ & $\begin{array}{l}17 \\
(2.3 \%)\end{array}$ & $\begin{array}{l}108 \\
(5.2 \%)\end{array}$ & 0.001 \\
\hline Urinology & $\begin{array}{l}114 \\
(4.1 \%)\end{array}$ & $\begin{array}{l}32 \\
(4.4 \%)\end{array}$ & $\begin{array}{l}82 \\
(3.9 \%)\end{array}$ & 0.606 \\
\hline Anesthesiology & $\begin{array}{l}113 \\
(4.0 \%)\end{array}$ & $\begin{array}{l}32 \\
(4.4 \%)\end{array}$ & $\begin{array}{l}81 \\
(3.9 \%)\end{array}$ & 0.566 \\
\hline Rehabilitation & $\begin{array}{l}104 \\
(3.7 \%)\end{array}$ & $\begin{array}{l}20 \\
(2.7 \%)\end{array}$ & $\begin{array}{l}84 \\
(4.0 \%)\end{array}$ & 0.109 \\
\hline $\begin{array}{l}\text { Plastic and reconstructive } \\
\text { surgery }\end{array}$ & $\begin{array}{l}101 \\
(3.6 \%)\end{array}$ & $\begin{array}{l}19 \\
(2.6 \%)\end{array}$ & $\begin{array}{l}82 \\
(3.9 \%)\end{array}$ & 0.094 \\
\hline Radiology & $\begin{array}{l}38 \\
(1.4 \%)\end{array}$ & $8(1.1 \%)$ & $\begin{array}{l}30 \\
(1.4 \%)\end{array}$ & 0.484 \\
\hline
\end{tabular}

knowledge" (1628, 57.9\%, male 392, 53.6\%, female 1236, 59.4\% P = $0.007)$, “(iv) Doctors who are rooted in the community" (1373, $48.8 \%$, male $366,50.1 \%$, female $1007,48.4 \%$; $\mathrm{P}=0.435)$, “(i) Doctors who are familiar with state of the art medical technologies" (783, 27.8\%, male 253, 34.6\%, female 530, 25.5\%; P = 0.000), "(vi) Doctors who have excellent medical technique (e.g. surgical technique)" (539, 19.2\%, male 137, 18.7\%, female 402, 19.3\%; P = 0.734), and "(iii) Doctors with strong training in a particular field of medicine" $(433,15.4 \%$, male 135 , $18.5 \%$, female $298,14.3 \%$; $\mathrm{P}=0.008)$. A chi-square test shows the sex differences in affirmative answers with a statistically significant $p$ value. Figure 6 shows the relationship between the affirmative answers to question (11) and the age groups of respondents. Affirmative answers to parts (ii), (iv) and (v) were increased among working-age respondents. However, affirmative answers to parts (i), (iii) and (vi) were not affected by the age group of respondents.

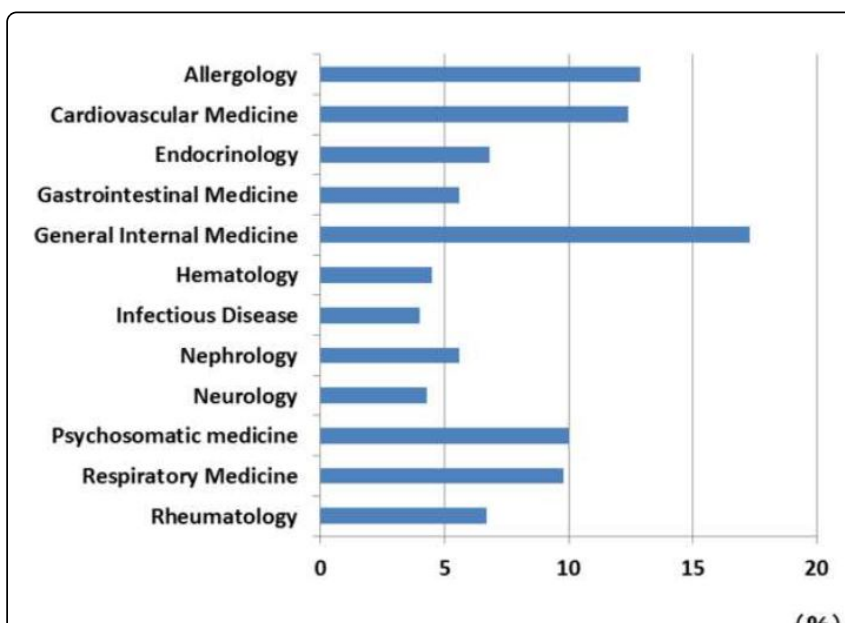

Figure 4: Medical specialties particularly lacking in physicians, as reported by respondents who answered "internal medicine" to question (8) (up to three choices) (total $=100 \%$ ).

Table 1: Claims of respondents for the lack of doctors in each medical field.Medical fields that respondents felt were particularly lack in number of physicians (up to three choices, total $=100 \%$ ). For each filled, sex difference was statistically analyzed by chi-square test.

(9) The respondents (469 people) who answered "internal medicine" to question felt that the medical specialty most lacking in physicians was general internal medicine $(124,17.3 \%)$, followed by allergology (93, 12.9\%), cardiovascular medicine $(89,12.4 \%)$, psychosomatic medicine $(72,10.0 \%)$, respiratory medicine $(70,9.8 \%)$, endocrinology $(49,6.8 \%)$, rheumatology $(48,6.7 \%)$, gastrointestinal medicine $(40$, $5.6 \%)$, nephrology (40,5.6\%), hematology (32, 4.5\%), neurology ( 31 , $4.3 \%)$, and infectious disease $(29,4.0 \%)$ (Figure 4$)$.

(10) The respondents (265 people) who answered "surgery" to question (8) felt that the surgical specialty most lacking in surgeons was general surgery $(103,33.2 \%)$, followed by cardiovascular surgery $(52,16.8 \%)$, pediatric surgery $(52,16.8 \%)$, gastrointestinal surgery $(29$, $9.4 \%)$, breast surgery $(29,9.4 \%)$, thoracic surgery $(23,7.4 \%)$, and respiratory surgery $(22,7.1 \%)$ (Figure 5).

(11) In terms of medical student development, the largest number of respondents hoped for "(v) Doctors who are empathetic with patients" (1683, 59.9\%, male 362, 21.5\%, female1321, 63.5\%; P = 0.000), followed by "(ii) Doctors who can provide general care based on broad

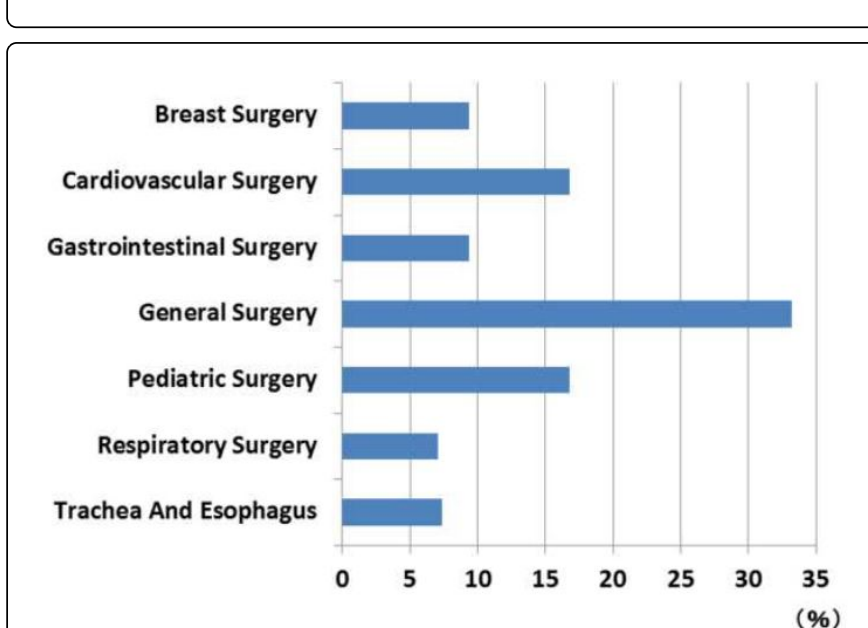

Figure 5: Surgical specialties particularly lacking in physicians, as reported by respondents who answered "surgery" to question (8) (up to three choices) $($ total $=100 \%)$. 
Citation: Toshiaki Takahashi, Onishi Sachiko, Kiyonori Takada, Naoto Kobayashi (2016) A Questionnaire Survey in Ehime Prefecture, Japan Revealed the Residents' Preferences for Community Medicine and Medical Education. Gen Med (Los Angeles) 4: 232. doi: $10.4172 / 2327-5146.1000232$

Page 5 of 8

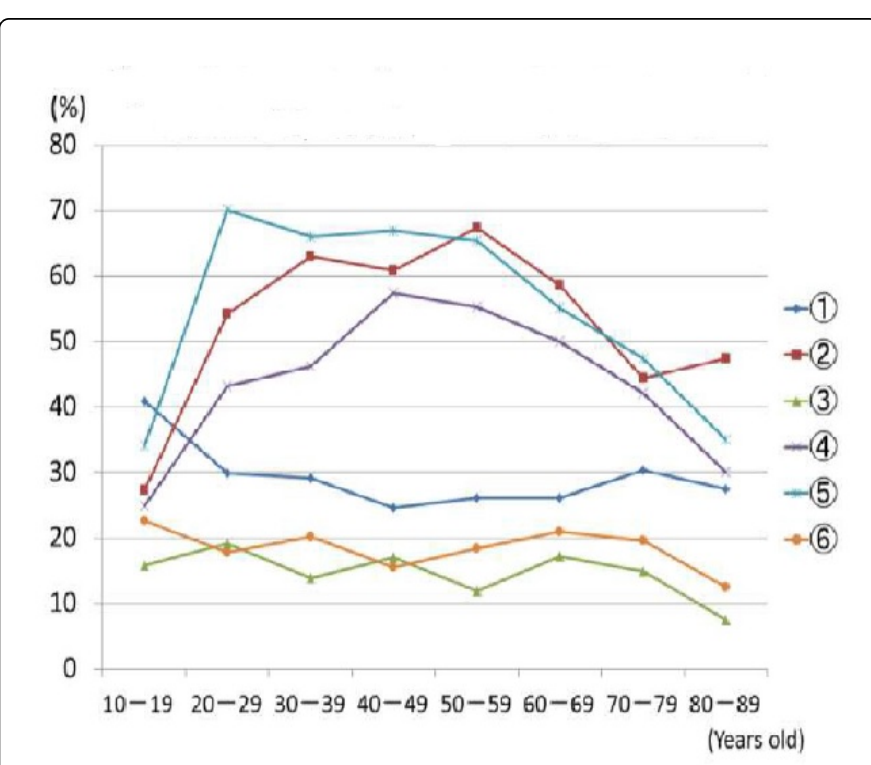

Figure 6: The relationship between affirmative answers to question (11) and the age groups of respondents. (i) doctors who are familiar with state of the art medical technologies. (ii) doctors who can provide general care based on broad knowledge. (iii) doctors with strong training in a particular field of medicine. (iv) doctors who are rooted in the community. (v) doctors who are empathetic with patients. (vi) doctors who have excellent medical technique (e.g. surgical technique).

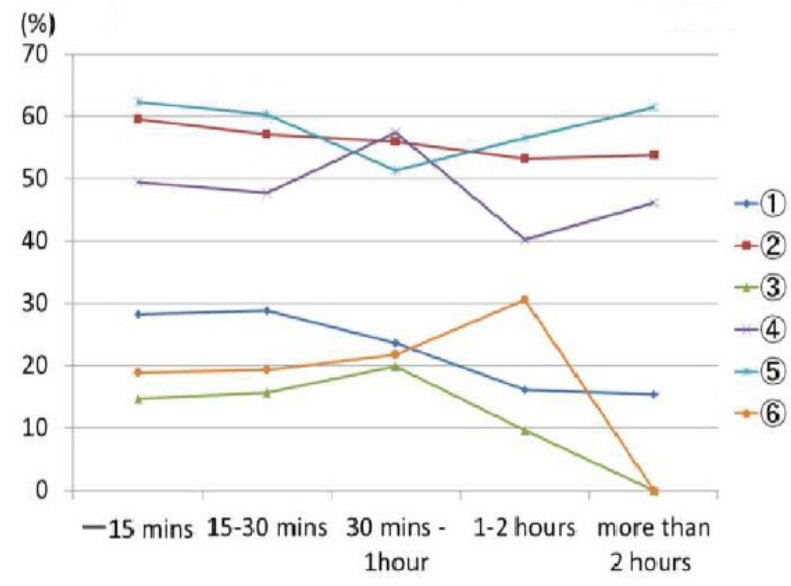

Figure 7: The relationship between affirmative answers to question (11) and the amount of time required for transportation. (i) doctors who are familiar with state of the art medical technologies. (ii) doctors who can provide general care based on broad knowledge. (iii) doctors with strong training in a particular field of medicine. (iv) doctors who are rooted in the community. (v) doctors who are empathetic with patients. (vi) doctors who have excellent medical technique (e.g. surgical technique).
Figure 7 shows the relationship between affirmative answers to question (11) and the amount of time required for transportation. Affirmative answers to parts (i), and (iii) were slightly decreased if the time required for transportation was greater. However, affirmative answers to parts (ii), (iv), (v) and (vi) were not changed by the time required for transportation.

Regarding measures to attract young physicians to the community, the largest number of respondents were in favor of "(v) Establishing hospital systems that accept trainees" (1550, 55.1\%, male 371, 50.8\%, female $179,56.7 \%$; $\mathrm{P}=0.006$ ), followed by "(ii) Launching the city or town's own scholarship fund to attract students to the community" (1285, 45.7\%, male 348, 47.6\%, female 937, 45\%; P = 0.228), “(iii) Encouraging local high school students to go to the local university's school of medicine" $(680,24.2 \%$, male $193,26.4 \%$, female $487,23.4 \%$; P $=0.103$ ), "(iv) Increasing the salary of young physicians working at local hospitals" (549, 19.5\%, male 168, 23\%, female 381, 18.3\%; P = $0.006)$, and "(i) inviting medical students to local festivals or events" (403, $14.3 \%$, male $124,17 \%$, female $279,13.4 \%$; $\mathrm{P}=0.018$ ). A chisquare test revealed the sex differences in affirmative answers with a statistically significant p-value. Figure 8 shows the relationship between affirmative answers question (12) and the age groups of respondents. Affirmative answers to parts (ii) and (v) were increased in working-age respondents. However, affirmative answers to part (i) gradually decreased as respondents' age group increased.

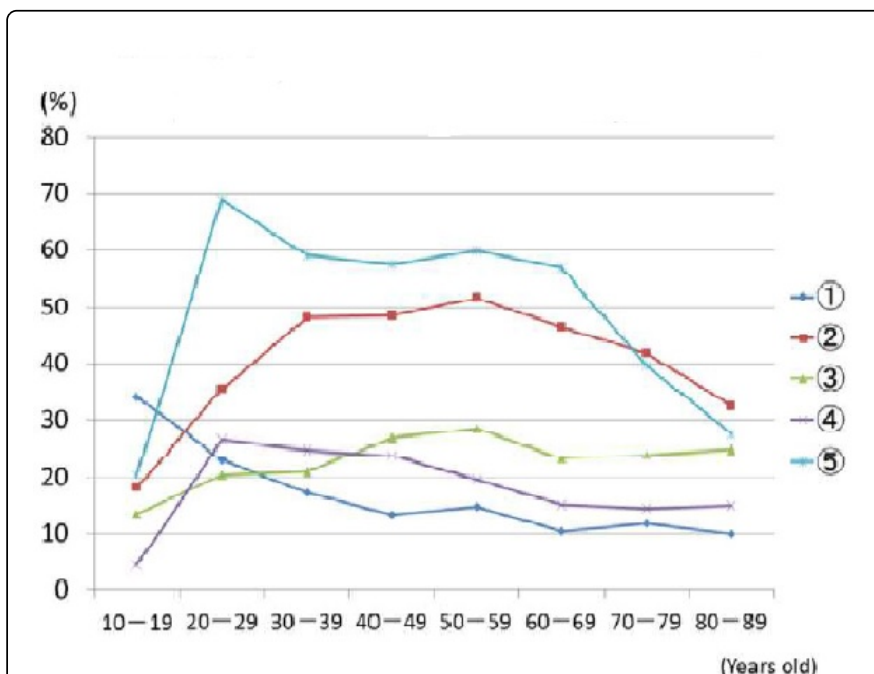

Figure 8: The relationship between affirmative answers to question (12) and the age groups of respondents. (i) inviting medical students to local festivals or events. (ii) launching the city or town's own scholarship fund to attract students to the community. (iii) encouraging local high school students to go to the local university's school of medicine. (iv) increasing the salary of young physicians working at local hospitals. (v) establishing hospital systems that accept trainees.

Figure 9 shows the relationship between affirmative answers to question (12) and the amount of time required for transportation. Affirmative answers to part (ii) was decreased in respondents for which the required time for transportation was over 2 hours. Overall, affirmative answers were not affected by the time required for transportation. 


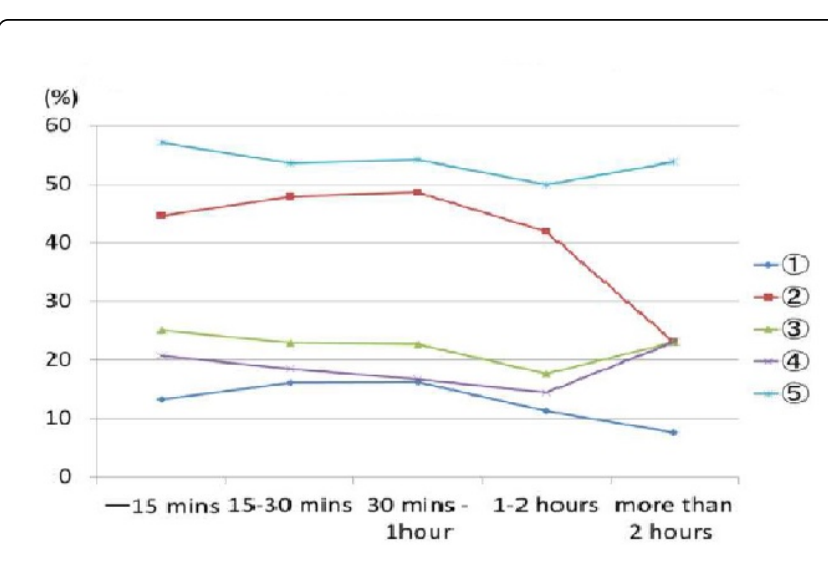

Figure 9: The relationship between affirmative answers to question (12) and the amount of time required for transportation. (i) inviting medical students to local festivals or events. (ii) launching the city or town's own scholarship fund to attract students to the community. (iii) encouraging local high school students to go to the local university's school of medicine. (iv) increasing the salary of young physicians working at local hospitals. (v) establishing hospital systems that accept trainees.

\section{Discussion}

\section{Overview of the survey}

In this survey, the valid recovery rate for Matsuyama City, the city with the largest population in the prefecture, was quite low at $24.4 \%$, while those for the regions other than Matsuyama City were all above $70 \%$, resulting in the very high mean value of $94.9 \%$ (76.0\% in total for the entire prefecture). Therefore, this survey is considered to be an accurate assessment of community medicine in the prefecture, although it could primarily reflect the responses of residents in lesspopulated regions.

Most of the respondents were elderly, with the largest 10-year age group being the 60s; the other age groups (from the 30 s to $70 \mathrm{~s}$ ) had similar numbers of respondents. Females comprised the majority of respondents in all age groups ( $74 \%$ on average). A large number of residents felt there is a particular lack of physicians in the femaleoriented fields of gynecology and pediatrics [1], however, sex difference of respondents was not seen in both departments. Department regarding of skin and parts of face in female was more than that of male. The type of medical facility used most frequently by respondents was the general hospital, followed by clinics such as independent hospitals. This indicates community residents' preference for general hospitals rather than clinics.

As for methods of transportation, private cars were used most frequently (by three-quarters of all respondents), followed by bicycles. These findings differ considerably from those in urban areas [6,7], because forms of public transportation such as busses and trains, which are well-established in urban areas, have not yet been introduced in the communities targeted by this survey. Nevertheless, ninety percent of respondents spent 30 minutes or less traveling to the medical facilities they visited most frequently. This was far less time than we had expected, as it was generally assumed that residents in non-urban areas required significant amounts of time to travel to their medical facilities. Our findings might be explained by the minimal traffic outside of cities, as well as less time waiting for public transportation. It should be noted that in cases of elderly individuals who are unable to drive, traveling to hospitals in private cars may place a burden on patients' families. The number of respondents who visited university hospitals most frequently was $3.7 \%$ of the total sample, and it is possible that this group increased the average transportation time required. Of the total sample, $2.5 \%$ took one hour or more to travel to medical facilities. We should promptly address this issue, particularly given the travel difficulties faced by elderly people. It may also be necessary to use the national budget to support the deployment of mobile clinics in less-populated regions.

\section{Physicians' specialty requested}

To date, the assignment of physicians to community hospitals has been based on these hospitals individual requests to independent physicians or to each specialty's university hospital offices. This process is not considered to accurately reflect the needs of community residents. Since these are the individuals who visit the community medical facilities and receive their services, meeting their needs to the greatest extent possible should enhance the hospitals' values in the communities and directly contribute to improving their management, including their financial status. Considering that our country now has fewer physicians compared to other developed countries, it is very important to reduce the number of underserved areas by appropriately assigning the small number of existing physicians $[8,9]$.

Our results also showed that the number of internal medicine physicians in rural areas was insufficient. Although residents of these areas now benefit from high-quality medicine due to the progressive advancement of internal medicine, general practitioners (home doctors) who can cover a broad range of internal medical issues are still needed. This finding has implications for the future direction of community medicine [10]. A previous survey regarding the career path preferences of medical students and junior trainees showed the greatest degree of interest in general internal medicine [11], which coincides with the community residents' preferences identified in this study. Respondents perceived a lack of physicians in general internal medicine, as well as in several internal medicine specialties: cardiovascular medicine, in which patients are often elderly; allergology, characterized by an increasing number of cases including many that can be serious; and psychosomatic medicine, which treats a large number of people with mental illness. These specialties are also considered to be insufficiently represented in urban areas. Respondents in this study also hoped for increased numbers of physicians in specialties such as emergency medicine and neurosurgery, which play important roles in treating urgent injuries and symptoms. On the other hand, they did not perceive a significant lack of physicians in radiology, anesthesiology, or rehabilitation, despite the fact that these fields also play important roles in hospitals. Respondents may have answered this question based on their familiarity with the outpatient services provided by physicians.

Few studies to date have conducted surveys on community residents' attitudes towards medicine and physicians at a large-scale, prefecture level. Therefore, based on the data obtained by our survey, we aim to help improve the distribution of physicians in Ehime Prefecture by cooperating with the prefecture, as well as cities' and towns' Departments of Medical Care and Public Aid, and their medical associations. We also aim to provide appropriate advice and guidance 
Citation: Toshiaki Takahashi, Onishi Sachiko, Kiyonori Takada, Naoto Kobayashi (2016) A Questionnaire Survey in Ehime Prefecture, Japan Revealed the Residents' Preferences for Community Medicine and Medical Education. Gen Med (Los Angeles) 4: 232. doi: $10.4172 / 2327-5146.1000232$

Page 7 of 8

to the community's hospitals and clinics via universities' postgraduate clinical training centers and Community Medicine Support Centers.

\section{Improvement of regional policy for community medicine}

With regard to measures to attract young physicians to the community, the largest numbers of respondents were in favor of establishing and enhancing community hospitals' training support systems [12]. It is important that community hospitals develop their own postgraduate clinical training programs, featuring advantages unique to each community [13]. It is also essential to ensure that trainees have a high quality of life while living in the community, with improved living environments and support programs. To achieve this, it is necessary to share best practices among neighboring hospitals, continuously enhance training programs, and to listen to the trainees' opinions, all under close collaboration with each community's major hospitals and university hospitals' postgraduate clinical training centers [14-16].

In addition, a large number of residents had positive attitudes toward providing scholarship funds for medical students from their cities or towns, so it is expected that such scholarship systems will be enhanced in the future. This may be difficult, however, given that most of the cities and towns in the prefecture currently have financial difficulties; solid financial support is also required to train competent physicians who provide high-quality care. Specifically, prolonged training in a single region or hospital may not produce a well-balanced physician, and is particularly inadequate for young physicians (up to 10 years following graduation). It may therefore be effective to develop scholarship programs in collaboration with those of other cities or towns in the prefecture. A large number of prefectures including Ehime have, in fact, launched scholarship programs to attract medical students who will continue to live in the community and provide medical care there. It will be essential to pay close attention to this training system's efficacy and use the lessons learned to improve similar programs in the future [13]. We hope this paper will promote improvements in community medicine while also guiding junior residents' decisions regarding specialties and helping to promote appropriate physician staffing.

\section{Limitations of this survey}

One limitation of our questionnaire survey was that it did not use a randomly sampled subject population, as we asked cities and towns to distribute and collect the questionnaires during opportunities such as events they hosted. In addition, some respondents might have answered questions based on information they received from the mass media or other institutions or individuals. However, in general, this survey was designed to identify the respondents' actual experiences with physician shortages, and was in fact somewhat reflective of each region's current status regarding physician labor. Thus, detailed measures should replicate this study using strictly random sampling and compare its results with those of the present investigation.

\section{Conclusions}

In today's society, community medicine plays a very important role in the continuing existence and vitalization of regional communities. It is therefore necessary to promote improvements in this field so that higher-quality medical care will be provided, without requiring lengthy travel, in any given community. We surveyed 2834 people by questionnaire regarding community medicine in Ehime Prefecture,
Japan. In order to attract young physicians to the community, the majority of respondents were in favor of establishing a community hospital system that would accept those with excellent postgraduate medical training.

\section{Competing Interests}

None declared.

\section{Acknowledgments}

We are grateful to Mr. Tetsuro Yamazaki and Ms. Rieko Takaoka of the Community Medicine Support Center for the entry of questionnaire data.

This study was conducted under Ehime Prefecture's Project on Doctor Training and Career Support 2012, and approved by the Community Medicine Promotion Committee of Ehime University Hospital.

\section{References}

1. Saruta K, Kawatani Y, Tahara K (2013) Survey on the number of required doctors, web site of the Ministry of Health, Labour and Welfare.

2. Kobayashi Y, Takaki H (1992) Geographic distribution of physicians in Japan. Lancet 340: 1391-1393.

3. Tanihara S, Kobayashi Y, Une H, Kawachi I (2011) Urbanization and physician maldistribution: A longitudinal study in Japan. BMC Health Services Research 11: 260.

4. Yuji K, Imoto S, Yamaguchi R, Matsumoto T, Murashige N, et al. (2012) Forecasting Japan's physician shortage in 2035 as the first full-fledged aged society. PLOS ONE 7: e50410.

5. Ikai T, Mutoh O, Yamamoto C, Hayama S, Terasawa S (2011) Reform of community medicine in Takahama town, fukui prefecture through collaboration among medical institutes, administrative agency, and universities-aiming to cultivate doctors and residents who support the community (The 2nd Report). Community Medicine The 50th special edition: 1411-1414.

6. Dhingra SL (2010) The urban transportation planning in developing countries. Journal of adv tran 27: 225-226.

7. Pratik R, Borkar SD, Ghodmare (2014) Sustainable public transportation system for emerging metropolitan cite. IOSR Journal of Mechanical and Civil Engineering 11: 11-14.

8. Matsumoto M, Inoue K, Kajii E, Takeuchi K (2010) Retention of physicians in rural Japan: Concerted efforts of the government, prefectures, municipalities and medical schools. Rural Remote Health 10: 1432.

9. Rivo ML, Kindig DA (1996) A report card on the physician work force in the United State. N Engl J Med 334: 892-896.

10. Brooks RG, Walsh M, Mardon RE, Lewis M, Clawson A (2002) The roles of nature and nurtune in the recruitment and retention of primary care physicians in rural areas: A review of the literature. Acad Med 77: 790-798.

11. Takeda Y, Morio K, Snell L, Otaki J, Takahashi M, et al. (2013) Characteristic profiles among students and junior doctors with specific career preferences. BMC Medical Education 13: 125.

12. Gupta TKS, Murray RB, McDonell A, Murphy B, Underhill AD (2008) Rural internships for final students: clinical experience, education and workforce. Rural Remote Health 8: 827.

13. Matsumoto M, Inoue K, Kajii E (2010) Policy implications of a financial incentive programme to retain a physician workforce in underserved Japanese rural areas. Social Science \& Medicine 71: 667-671.

14. Curran V, Rourke J (2004) The role of medical education in the recruitment and retention of rural physicians. Med Teach 26: 265-272. 
Citation: Toshiaki Takahashi, Onishi Sachiko, Kiyonori Takada, Naoto Kobayashi (2016) A Questionnaire Survey in Ehime Prefecture, Japan Revealed the Residents' Preferences for Community Medicine and Medical Education. Gen Med (Los Angeles) 4: 232. doi: $10.4172 / 2327-5146.1000232$

Page 8 of 8

15. Ishimaru N, Takayashiki A, Maeno T, Kawamura $\mathrm{Y}$, Kurihara H, et al (2015) The impact of an early-exposure program on medical students interest in and knowledge of rural medical practices: a questionnaire survey. Asia Pacific Family Medicine 14: 3
16. Matsumoto M, Okayama M, Inoue K, Kajii E (2005) Factors associated with rural doctors' intention to continue a rural career: A survey of 3072 doctors in Japan. Aust J Rural Health 13: 219-225. 